\title{
Multi-breed Genetic Parameters and Genome-wide Association Studies for Mortality Rate at Birth in Pigs
}

\section{Meijing An}

HZAU: Huazhong Agriculture University

\section{Guangliang Zhou}

HZAU: Huazhong Agriculture University

\section{Yang Li}

HZAU: Huazhong Agriculture University

\section{Tao Xiang}

HZAU: Huazhong Agriculture University

\section{Yunlong Ma}

HZAU: Huazhong Agriculture University

Xiaolei Liu

HZAU: Huazhong Agriculture University

\section{Xinyun Li}

HZAU: Huazhong Agriculture University

\section{Shuhong Zhao}

HZAU: Huazhong Agriculture University

Mengjin Zhu ( $\sim$ zhumengjin@mail.hzau.edu.cn )

Huazhong Agricultural University: Huazhong Agriculture University https://orcid.org/0000-0001-89315022

\section{Research}

Keywords: mortality rate at birth, heritability, genetic correlation, GWAS, pig

Posted Date: January 15th, 2021

DOI: https://doi.org/10.21203/rs.3.rs-146253/v1

License: (c) (1) This work is licensed under a Creative Commons Attribution 4.0 International License.

Read Full License 


\section{Title page}

\section{Multi-breed genetic parameters and genome-wide}

\section{association studies for mortality rate at birth in pigs}

Meijing An ${ }^{1}$, Guangliang Zhou ${ }^{1}$, Yang Li ${ }^{1}$, Tao Xiang ${ }^{1,2}$, Yunlong Ma ${ }^{1,2}$, Xiaolei

Liu ${ }^{1,2}$, Xinyun $\mathrm{Li}^{1,2}$, Shuhong Zhao ${ }^{1,2}$ and Mengjin $\mathrm{Zhu}^{1,2^{*}}$

1 Key Lab of Agricultural Animal Genetics, Breeding, and Reproduction of Ministry of Education, Huazhong Agricultural University, Wuhan 430070, China

2 The Cooperative Innovation Center for Sustainable Pig Production, Huazhong Agricultural University, Wuhan 430070, China

*Correspondence: Mengjin Zhu zhumengjin@mail.hzau.edu.cn

Meijing An

Guangliang Zhou

Yang Li

Tao Xiang

Yunlong Ma

Xiaolei Liu

Xinyun Li

Shuhong Zhao

Mengjin Zhu anmeijing521@gmail.com

glzhou@webmail.hzau.edu.cn yli@webmail.hzau.edu.cn

Tao.Xiang@mail.hzau.edu.cn

Yunlong.Ma@mail.hzau.edu.cn

xiaoleiliu@mail.hzau.edu.cn

xyli@mail.hzau.edu.cn

shzhao@mail.hzau.edu.cn

zhumengjin@mail.hzau.edu.cn 


\title{
${ }_{2}$ Multi-breed genetic parameters and genome-wide 3 association studies for mortality rate at birth in pigs
}

\begin{abstract}
4 Abstract
5 Background

6 Piglet mortality is an economically important complex trait that impacts sow prolificacy in the 7 pig industry. The genetic parameters estimations and genome-wide association studies will 8 help us to better understand the genetic fundamentals of piglet mortality. However, compared 9 with other economically important traits, a little breakthrough in the genetic analyses of the 10 trait has been achieved.
\end{abstract}

\section{Results}

12 In this study, we used multi-breed data sets from Yorkshire, Landrace, and Duroc sows and 13 characterized the genetic and genomic properties of mortality rate at birth by treating each 14 parity as a different trait. The heritability of mortality rate from parity I to III were estimated 15 to be $0.0630,0.1031$, and 0.1140 , respectively. The phenotypic and genetic correlations with 16 its component traits were all positive with ranges from 0.0897 to 0.9054 , and 0.2388 to 0.9999 , 17 respectively. Integrating the results, we identified 21 loci that were detected at least by two 18 tools from standard MLM, FarmCPU, BLINK and mrMLM, and these loci were annotated to 1922 genes. The annotations revealed that the gene expressions were associated with the 20 reproductive system, nervous system, digestive system, and embryonic development, which 21 are reasonably related to the piglet mortality.

\section{Conclusions}

23 In brief, the genetic properties of piglet mortality at birth were reported. These findings are 24 expected to provide much information for understanding the genetic and genomic fundamentals 25 of farrowing mortality and also identify candidate molecular markers for breeding practice.

26 Keywords: mortality rate at birth, heritability, genetic correlation, GWAS, pig

\section{1. Background}

29 Piglet mortality-related traits are a category of economically important traits that provide direct 30 or indirect metrics of piglet deaths and produce heavy economic losses and welfare concerns 31 to the pig industry $(1,2)$. The majority of piglet mortality traits have been documented to be 
32 complex traits with low heritability ranging from 0.03 to 0.17 (3). In theory, the outcome of 33 mortality is the tri-interactions between piglet, sow and environment, and the phenotypic 34 variation could be caused by diverse systematic and non-systematic factors, including genetic 35 background (breed), parity, season, disease, management, piglet vitality, and sow's behavior 36 such as crushing and starvation (4-6). For the high economic merit, there has been a growing 37 emphasis on reducing piglet losses in pig breeding programs of some countries.

38 Past experiences from breeders revealed that selection on litter size increases piglet mortality 39 and the intensive couplings with litter size implied that there might exist strong negative 40 linkage disequilibrium (LD) or opposite pleiotropy in the cross-trait genetic architectures (7). 41 However, to date, there have been no more than 10 reports publicly available to describe the 42 genomic fundamentals of piglet mortality-related traits $(8,9)$. Compared with other 43 economically important traits, little breakthrough in the genetic dissections of piglet mortality44 related traits has been achieved. The limited progress cannot underpin a pinpoint understanding 45 of genetic properties of piglet mortality-related traits, and further efforts are needed.

46 There are usually two time points to measure mortality, including at birth and at weaning (10) 47 . No matter at weaning or at birth the mortality is measured, the metrics are derived from its 48 component traits, i.e. litter size-related traits. When dealing with piglet mortality as well as its 49 components, there remains an important concern for parity. It is still unable to reach a 50 consensus about how to treat this type of data sets in practice. In theory, during the first parities, 51 the reproductive organs of gilt are still undergoing developmental changes, while for higher 52 parity sows the risk of death increases due to oxytocin insufficiency and ruptured umbilical 53 cord (11). Given these, many researchers treated each parity as a different trait in genetic 54 analyses. For example, Roehe \& Kennedy (1995) reported that the genetic parameters of litter 55 size were estimated with each parity treated as a different trait (12). More studies revealed that 56 the estimations of genetic parameters varied between different parities in different pig cohorts $57(13,14)$. In addition, researchers also found that the reproductive traits in different parities had 58 a different genetic architecture (15). So, it's quite sound to treat each parity as a different trait.

59 There were growing studies that used multi-breed data sets for genetic parameter estimation 60 and GWAS. In general, the multi-breed approach has potential advantages, such as enlarging 61 the sample size by putting the multi-breed individuals together, capturing the genetic variants 62 both within and across breeds, and improving the accuracy of genetic evaluation. For example, 63 a simulation study has evaluated the efficiency of the multi-breed approach, and reported that 64 the multi-breed approach could improve the accuracy of genomic estimated breeding values 65 (GEBVs) for the second breed with fewer sizes (16). It was also found that the multi-breed 66 models had a positive effect on the genetic parameter estimations (17). Raven et al. (2014) 67 declared that the multi-breed approach could accurately locate the highly conserved functional 68 mutations because the mixed population had lower levels of long-range LD (18). The multi69 breed approach has been widely proven to be feasible in genetic analyses.

70 Knowledge of genetic property for a trait is involved in many aspects, in which genetic 71 parameters and genomic architecture are two important ones. The aim of this study was to 72 characterize the genetic property of mortality rate at birth using the mixture data sets from 
73 Yorkshire, Landrace, and Duroc sows. In this study, the genetic parameters including breeding 74 value, heritability, and genetic correlation between piglet mortality and its component traits 75 from parity I to III were estimated, and GWAS on piglet mortality was performed to identify 76 the genome-wide variants and putative genes underlying the variability of piglet mortality. This 77 study would accelerate our understanding of the molecular fundamentals of piglet mortality 78 and provides potential markers for pig breeding programs.

\section{2. Methods}

\section{2.1.Animals and phenotype collection}

81 Raw data sets were collected from southern China. The breeds in the data sets included 82 Yorkshire, Landrace and Duroc pigs. The raw records were produced from January 2014 to 83 June 2018. Considering that there were too many levels of farrowing dates, we re-formatted 84 them as the labels of seasons. According to the geographical location and weather condition of 85 the local farm, farrowing dates from March to May, from June to August, from September to 86 November, and from December to February of the following year were re-labeled as four 87 seasons. All available fixed factors were preliminarily tested by generalized linear model 88 (GLM), and only the fixed factors that passed the preliminary test were retained for model 89 establishment, which included breed, parity, and re-formatted season. In this study, the 90 mortality rate was derived from its component traits at birth, which was defined as the ratio of 91 the total number dead (TND) over the total number born (TNB). The component traits included 92 the total number born (TNB), the number of stillborn piglets (NS), and the number of 93 mummified at birth (NM). NS was the number of intrapartum deaths during farrowing, and $94 \mathrm{NM}$ was the number of antepartum deaths with tissue degeneration or absorption. The mortality 95 rate at birth was measured using the formula below:

96

$$
\text { Mortality }=\frac{T N D}{T N B}
$$

97 In the formula, $\boldsymbol{T N D}=\boldsymbol{N} \boldsymbol{S}+\boldsymbol{N} \boldsymbol{M}$. Considering the sample size, we analyzed the data set from 98 parity I to III, including 6,073 individuals from parity I, 5,415 individuals from parity II and 994,378 individuals from parity III. In total, there were 35,313 individuals in the pedigree that 100 were used to construct the numerator relationship matrix for estimations of genetic parameters. 101 A more detailed information about the data structure for raw data sets was shown in Additional 102 Table 1.

\section{2.2. Estimations of breeding value, heritability, and genetic correlation}

$104 \mathrm{We}$ implemented the pedigree-based best linear unbiased prediction to estimate the genetic 105 parameters, in which the breed and seasons were taken as fixed effects $(19,20)$. Based on the 106 multi-breed approach, estimations of estimated breeding value (EBV), heritability and genetic 107 correlation were calculated using the HIBLUP software developed by our lab 108 (https://hiblup.github.io). The mixed linear model was formulated as follow:

$$
y=X \beta+Z u+e
$$


110 In the model, $y$ was a vector of observations, $\beta$ is a vector of fixed effects, including the fixed 111 mean, breed, and re-formatted season (19); $\mathrm{u} \sim \mathrm{N}(0, \mathrm{G})$ was a vector of breeding values, and $\mathrm{G}$ $112 \sim \mathrm{A} \sigma_{\mathrm{a}}^{2}$, in which $\sigma_{\mathrm{a}}^{2}$ was additive genetic variance and $\mathrm{A}$ was an additive genetic relationship 113 matrix derived from the pedigree structure; $\mathrm{e} \sim \mathrm{N}\left(0, \mathrm{I} \sigma_{\mathrm{e}}^{2}\right)$ represented the residuals, where $\sigma_{\mathrm{e}}^{2}$ 114 was the residual variance. $\mathrm{X}$ and $\mathrm{Z}$ were design matrices for $\beta$ and $\mathrm{u}$, respectively. When 115 estimating genetic correlations, the bivariate models had the same components as the univariate 116 models, and the between-trait genetic and residual variance-covariance structures were defined 117 as $\left[\begin{array}{cc}\sigma_{a_{x}}^{2} A & \sigma_{a_{x} a_{y}} A \\ \sigma_{a_{y} a_{x}} A & \sigma_{a_{y}}^{2} A\end{array}\right]$ and $\left[\begin{array}{cc}\sigma_{e_{x}}^{2} & \sigma_{e_{x} e_{y}} \\ \sigma_{e_{y} e_{x}} & \sigma_{e_{y}}^{2}\end{array}\right]$, in which A was additive genetic relationship 118 matrix, $\sigma_{\mathrm{a}}^{2}$ was additive genetic variance, $\sigma_{\mathrm{e}}^{2}$ was the residual variance, $\sigma_{a_{x} a_{y}}$ was the 119 genetic covariance between two traits, $\sigma_{e_{x} e_{y}}$ was the residual covariance between two traits, 120 and the subscripts $\mathrm{x}$ and $\mathrm{y}$ denoted two traits. The average information restricted maximum 121 likelihood (AI-REML) algorithm, i.e., iterative algorithm based on Newton iteration and Fisher 122 score method, was used for (co)variance components estimation.

\section{2.3. DNA isolation, genotyping and quality control}

124 Ear tissue samples were collected and stored in freezers at $-20^{\circ} \mathrm{C}$. Genomic DNA was extracted 125 using Tecan Freedom EVO NGS workstation and magnetic animal tissue genomic DNA kit 126 (TIANGEN) according to the manufacturer's protocol. In total, 1,331 individuals were 127 genotyped, of which 1,331 individuals had phenotypic data in parity I, 1,220 individuals in 128 parity II, and 980 individuals in parity III. Genotyping was conducted using the Illumina 129 PorcineSNP60 Bead Chip. All SNPs were mapped to Sus scrofa genome build 11.1 (21). When 130 performing quality control (QC), the SNPs with call rates $\leq 90 \%$, minor allele frequencies $\leq$ 131 1\% were removed by PLINK (22). The missing genotypes were imputed by Beagle software 132 (23) and the imputed genotype data were also filtered, using the same conditions as the former.

\section{2.4. GWAS and integration of results}

134 To increase the detection credibility, we used a combined approach for GWAS. Concretely 135 speaking, four tools, including the standard MLM, FarmCPU (R package "rMVP") (24), 136 BLINK, and mrMLM, were simultaneously used to perform the GWAS analyses (25-28), and 137 then combined the results from four tools. In the integration, considering that the Bonferroni 138 correction is usually too conservative and may miss putative SNPs with medium effect size in 139 GWAS (29), after normal GWAS analyses, we alternatively used a soft-cutoff to determine the 140 putative SNPs, in which we first sorted the SNPs according to the p-values, and then made the 141 intersections between different tools with following a permutation test procedure to statistically 142 confirm the validity of selection of putative SNPs. It was reported that independent replication 143 in a different cohort provides a gold standard approach for identification of putative SNPs (30), 144 and here, borrowing the similar idea, the SNPs that were repeatedly identified at least by two 145 different tools were suggested as putative SNPs. Simultaneously, considering that the 146 permutation test is computationally intensive, for each tool and each parity, no matter what the 147 p-value was, only top 10 SNPs were selected for combined analyses. For permutation test, with 148 10,000 random shuffles of real phenotypes, the MLM-based GWAS technique were repeatedly 149 conducted to produce 10,000 pseudo p-values. In the distribution of pseudo p-values of 150 permutation test, the position of raw $\mathrm{p}$-value was referenced to determine the permutated $\mathrm{p}$ 151 values of target SNPs. Here, according to the principle of small probability in statistics, if a p152 value derived from the real data is less than the pseudo p-value at quantile 0.05 or 0.01 of the 153 permutated distribution, the $\mathrm{p}$-value is defined to be statistically or high statistically significant. 


\section{2.5. Gene annotations}

155 The genes harboring or closely neighboring the identified SNPs were confirmed by mapping 156 into Sus scrofa genome version v11.1. The chromosomal coordinate information was extracted 157 to annotate the candidate genes by selecting the closest gene for each identified SNP based on 158 the Ensembl database (http://uswest.ensembl.org/Sus_scrofa/Info/Index). We used the latest 159 version of the TISSUES database (TISSUES 2.0) to reconstruct the digital expression profiles 160 of putative genes from different tissues, where the top 20 tissues with high confidence score 161 were selected to visualize the gene-tissue expression relationships through the heat map (31).

\section{Results}

\section{3.1. Distributions of phenotypes and breeding values for piglet mortality}

164 The distributions of phenotypes and EBVs from parity I to III were shown in Figure 1, where 165 the phenotypic distributions were shown in the sub-figures from A to C, and EBVs in the sub166 figures from $\mathrm{D}$ to $\mathrm{F}$. In this study, the piglet mortality was defined as a ratio trait that is 167 calculated as the ratio of total number dead (TND) over total number born (TNB). In usual, a 168 ratio trait is departure from the normal distribution, and it was found that the phenotypes of 169 piglet mortality from parity I to III followed a heavy skewed distribution. Compared with the 170 heavy skewed distribution of phenotypes, all distribution curves of the EBVs from parity I to 171 III had two tails with a positively skewed distribution, which were relatively closer to the 172 normal distribution. For more detailed information, the descriptive statistics of raw data sets 173 was given in Additional Table 4.
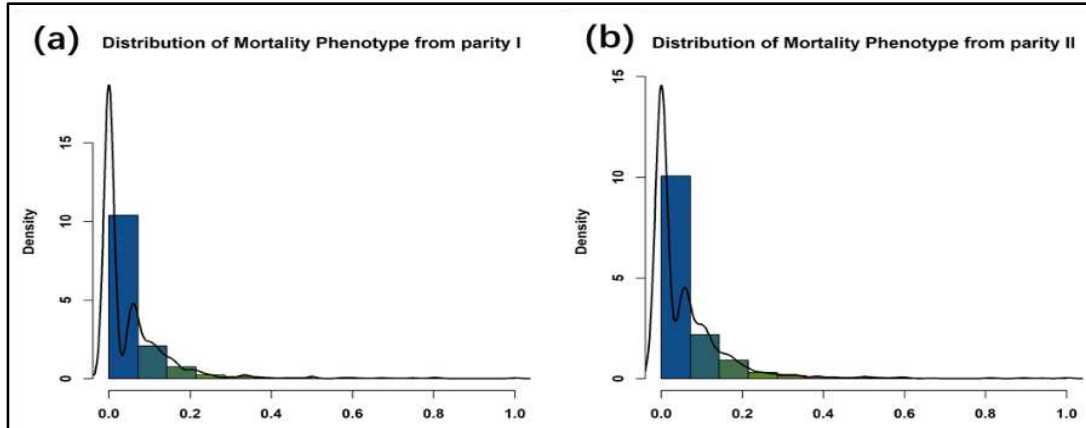

(c) Distribution of Mortality Phenotype from parity III

(d) Distribution of Mortality EBV from parity 1

(e)



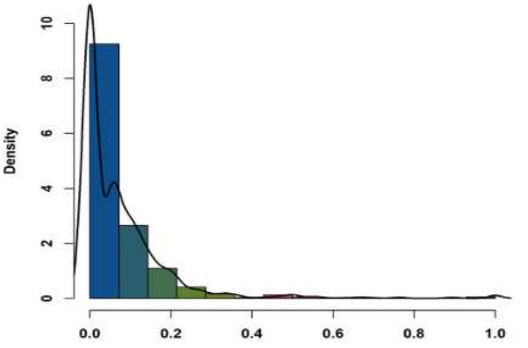

(f)

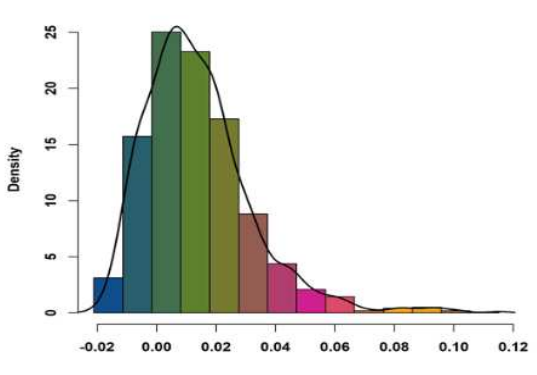

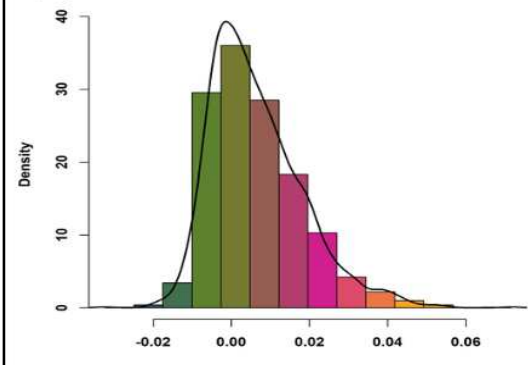

Figure 1. The phenotypic and EBV's distributions of piglet mortality from the three parities. Sub-figures from a to c represented the phenotypic distributions from parity I to parity III, and sub-figures from $\mathrm{d}$ to f represented the distributions of EBVs from parity I to III, respectively. 


\section{3.2. Estimation of genetic parameters for piglet mortality and its component traits}

181 The results of heritability estimation for piglet mortality were presented in Table 1 . The 182 estimations of heritability from parity I to III were $0.0630,0.1031$ and 0.1140 , respectively. 183 According to the classification of heritability, the piglet mortality could be considered as a trait 184 with low heritability. Considering the difference of heritabilities between three parities, the 185 same trait from different parities could be taken as different traits. The heritabilities of the 186 component traits of piglet mortality were also listed in Additional Table 2. Table 2 showed the 187 estimations of genetic and phenotypic correlations between piglet mortality and its components 188 traits, including TNB, TND, NS, and NM. All genetic correlations were positive ones ranging 189 from 0.2388 to 0.9999 . For the same trait-pair, the estimations of genetic correlations much 190 differed in different parities. The differences of genetic correlation coefficients between three 191 parities also supported taking the same trait in different parities as different traits.

192 Table 1. Estimations of heritability and standard error (heritability \pm se) of piglet 193 mortality from parity I to III.

\begin{tabular}{llcl}
\hline Trait & Parity I & Parity II & Parity III \\
\hline Mortality rate & $0.0630 \pm 0.0219$ & $0.1031 \pm 0.0269$ & $0.1140 \pm 0.0285$ \\
\hline
\end{tabular}

194 Table 2. Estimations of genetic and phenotypic correlations between piglet mortality 195 and its component traits from parity I to III.

\begin{tabular}{llllll}
\hline Parity I & & & & & \\
\hline & TND & TNB & NS & NM & Mortality \\
TND & & 0.2306 & 0.6745 & 0.8258 & 0.8854 \\
TNB & 0.7042 & & 0.1526 & 0.1934 & 0.0442 \\
NS & 0.7301 & 0.9999 & & 0.1405 & 0.6347 \\
NM & 0.8952 & 0.2388 & 0.3491 & & 0.7030 \\
Mortality rate & 0.9999 & 0.6549 & 0.5816 & 0.9999 & \\
\hline Parity II & & & & & \\
\hline & TND & TNB & NS & NM & Mortality \\
TND & & 0.2692 & 0.6992 & 0.7748 & 0.8929 \\
TNB & 0.8245 & & 0.2062 & 0.1922 & 0.0903 \\
NS & 0.9382 & 0.8577 & & 0.0897 & 0.6485 \\
NM & 0.8679 & 0.5985 & 0.6424 & & 0.6745 \\
Mortality rate & 0.7747 & 0.617 & 0.8596 & 0.8131 & \\
\hline Parity III & & & & & \\
\hline & TND & TNB & NS & NM & Mortality \\
TND & & 0.2939 & 0.7390 & 0.7568 & 0.9054 \\
TNB & 0.6131 & & 0.2341 & 0.2057 & 0.1055 \\
NS & 0.9523 & 0.4940 & & 0.1189 & 0.6815 \\
NM & 0.7349 & 0.7471 & 0.4928 & & 0.6730 \\
Mortality rate & 0.9916 & 0.4896 & 0.9860 & 0.7773 & \\
\hline
\end{tabular}

196 Note: In each parity, the correlation coefficients and standard errors (bracketed) for 197 genetic correlations were in the lower triangle, and phenotypic correlations were in 198 the upper triangle. TND was the total number dead, TNB was the total number born, 199 NS was the number of stillborn piglets, and NM was the number of mummified at 200 birth. 


\section{3.3. Results of GWAS analyses for piglet mortality}

203 After quality control, a total of 47,241 SNPs were passed the filtering options. Principal 204 component analysis (PCA) was carried out and the scatterplot of the first two principal 205 components were displayed in Additional Figures S1. Four tools, including standard MLM, 206 FarmCPU, BLINK, and mrMLM were used to run the GWAS analyses. In the GWAS analyses, 207 the target trait from parity I to III have different sample sizes (parity I, $\mathrm{n}=1331$; parity II, $208 \mathrm{n}=1220$; parity III, $\mathrm{n}=980$ ). The top ten SNPs identified by each tool for each parity were listed 209 in Additional Table 5. After extracting and summarizing the results of GWAS, Figure 2 showed 210 the circular-Manhattan plots of piglet mortality traits from MLM, FarmCPU, BLINK, $211 \mathrm{mrMLM}$. In addition, the Venn diagrams were drawn to identify the intersections of the top ten 212 SNPs from four tools (Figure 3).

213 In total, 21 SNPs were identified, of which, 6 belonged to parity I, 5 belonged to parity II, and 21410 belonged to parity III. For the identified SNPs from different parities, no overlapping was 215 observed. All identified SNPs passed the permutation test, and were statistically confirmed. 216 The SNP symbols, the smallest p-values from GWAS, and permutated p-values of the 217 identified SNPs were listed in the Additional Table 3.

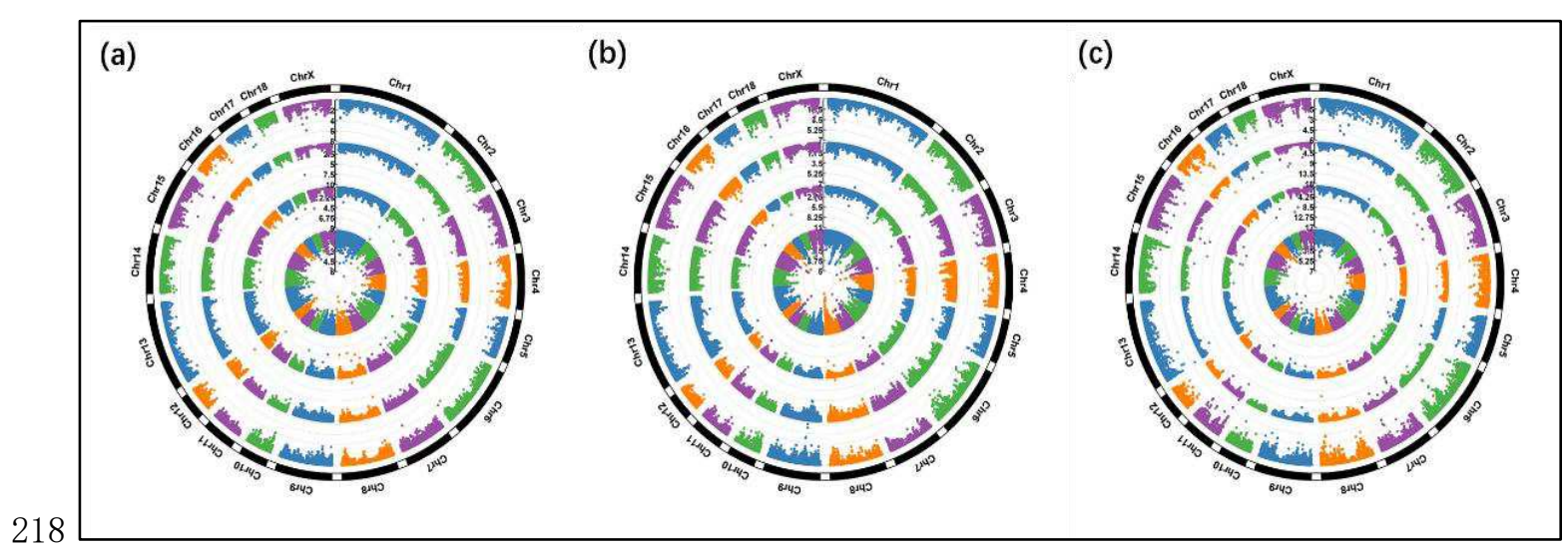

219 Figure 2. Circular-Manhattan of piglet mortality of different parities. a. Circular220 Manhattan plots of MLM, FarmCPU, BLINK, mrMLM for parity I; b. Circular221 Manhattan plots of MLM, FarmCPU, BLINK, mrMLM for parity II; c. Circular222 Manhattan plots of MLM, FarmCPU, BLINK, mrMLM for parity III; and from inner 223 to outer, they were MLM, FramCPU, BLINK and mrMLM, respectively.



Figure 3. The Venn diagrams of identified SNPs in piglet mortality from parity I, II, III a. Venn diagrams of MLM, FarmCPU, BLINK, mrMLM method for parity I. There were 6 SNPs intersected by at least two tools; b. Venn diagrams of MLM, FarmCPU, BLINK, mrMLM method for parity II. There were 5 SNPs intersected by two tools; 


\section{3.4. Gene annotations}

232 All SNPs that passed the permutation test were further used for gene annotations. In total, we 233 obtained 22 candidate genes that harbor or near the 21 identified SNPs. The position 234 information of 21 SNPs and corresponding 22 genes were shown in Table 3. Among them, the 235 positions of MARC0113660 and DRGA0008818 are located within 5.8kb, and there is only 236 one gene (STPG2) in this region. According to the annotation criterion, there were two genes 237 CDK8 and WASF3 that were both close to ALGA0060358. Three SNPs, including 238 ALGA0036320, H3GA0018655 and ASGA0029165, were annotated to be close to four genes 239 that included CABYR, OSBPL1A, IMPACT, and HRH4. It can be found that, among these 240 SNPs, there were totally eight SNPs clustered on SSC 8. Furthermore, we used the information 241 extracted from TISSUES database (TISSUES 2.0) to visualize the digital tissue expression 242 profiles for target genes. When drawing the heat map, three genes were dropped because there 243 was no expression information for them. At last, the heat map of tissue expressions for 19 244 annotated genes from different tissues was presented in Figure 3. The heat map revealed that 245 most of these genes have been expressed in reproductive and urinary system, nervous system, 246 and digestive system, and many expressions were detected in fetus. The tissue expression 247 profiles revealed that the identified genes are intuitively related to the physiological processes 248 contributing to piglet mortality, such as embryo development.

249 Table 3. The position information of 21 SNPs and corresponding 22 genes.

\begin{tabular}{|c|c|c|c|c|c|}
\hline Parity & SNP & Chrom & Position & Gene & Description \\
\hline \multirow[t]{6}{*}{$\mathbf{I}$} & $\begin{array}{l}\text { WU_10.2_2_133 } \\
608994\end{array}$ & 2 & $\begin{array}{l}12836572 \\
8\end{array}$ & ZNF608 & zinc finger protein 608 \\
\hline & $\begin{array}{l}\text { WU_10.2_6_149 } \\
29389\end{array}$ & 6 & 15567222 & $Z F H X 3$ & zinc finger homeobox 3 \\
\hline & ALGA0121819 & 8 & 77276189 & GATB & $\begin{array}{l}\text { glutamyl-tRNA } \\
\text { amidotransferase subunit } \\
\text { B }\end{array}$ \\
\hline & $\begin{array}{l}\text { WU_10.2_9_475 } \\
40573\end{array}$ & 9 & 42434488 & $C A D M 1$ & cell adhesion molecule 1 \\
\hline & $\begin{array}{l}\text { WU_10.2_10_43 } \\
18367\end{array}$ & 10 & 2665638 & BRINP3 & $\begin{array}{l}\text { BMP/retinoic acid } \\
\text { inducible neural specific } 3\end{array}$ \\
\hline & $\begin{array}{l}\text { WU_10.2_X_77 } \\
08900\end{array}$ & 23 & 7313289 & MID1 & midline 1 \\
\hline \multirow[t]{5}{*}{ II } & MARC0052132 & 3 & 14585248 & AUTS2 & $\begin{array}{l}\text { autism } \\
\text { candidate } 2\end{array}$ \\
\hline & $\begin{array}{l}\text { WU_10.2_7_694 } \\
5588\end{array}$ & 7 & 6732442 & MIR9802 & $\begin{array}{l}\text { let-7/miR-98 family } \\
\text { members are expressed } \\
\text { late in mammalian } \\
\text { embryonic development }\end{array}$ \\
\hline & ALGA0048798 & 8 & 99466642 & FAT4 & FAT atypical cadherin 4 \\
\hline & $\begin{array}{l}\text { WU_10.2_8_135 } \\
384225\end{array}$ & 8 & $\begin{array}{l}12626628 \\
6\end{array}$ & GRID2 & $\begin{array}{l}\text { glutamate ionotropic } \\
\text { receptor delta type subunit } \\
2\end{array}$ \\
\hline & ALGA0090390 & 16 & 37352844 & GAPT & $\begin{array}{l}\text { GRB2 binding adaptor } \\
\text { protein, transmembrane }\end{array}$ \\
\hline
\end{tabular}




\begin{tabular}{|c|c|c|c|c|c|}
\hline III & DRGA0001119 & 1 & 67860459 & $A S C C 3$ & $\begin{array}{l}\text { activating } \\
\text { cointegrator } \\
\text { subunit } 3\end{array}$ \\
\hline & Affx-115201707 & 1 & 79966051 & HS3ST5 & $\begin{array}{lr}\text { heparan } & \text { sulfate- } \\
\text { glucosamine } & 3- \\
\text { sulfotransferase 5 } & \end{array}$ \\
\hline & MARC0113660 & 8 & $\begin{array}{l}12208331 \\
9\end{array}$ & \multirow{2}{*}{ STPG2 } & \multirow{2}{*}{$\begin{array}{l}\text { sperm tail PG-rich repeat } \\
\text { containing } 2\end{array}$} \\
\hline & DRGA0008818 & 8 & $\begin{array}{l}12214134 \\
3\end{array}$ & & \\
\hline & \multirow[b]{2}{*}{ ALGA0060358 } & \multirow[b]{2}{*}{11} & \multirow[b]{2}{*}{4274441} & CDK8 & cyclin dependent kinase 8 \\
\hline & & & & WASF3 & $\begin{array}{l}\text { wiskott-Aldrich syndrome } \\
\text { protein family member } 3\end{array}$ \\
\hline & ASGA0049501 & 11 & 6324834 & MTUS2 & $\begin{array}{ll}\begin{array}{l}\text { microtubule } \\
\text { tumor }\end{array} & \begin{array}{l}\text { associated } \\
\text { suppressor }\end{array} \\
\text { candidate 2 } & \\
\end{array}$ \\
\hline & ASGA0055572 & 13 & 1323602 & NEK11 & $\begin{array}{l}\text { NIMA (never in mitosis } \\
\text { gene a)- related kinase } 11\end{array}$ \\
\hline & ALGA0036320 & 6 & $\begin{array}{l}10897605 \\
4\end{array}$ & CABYR & $\begin{array}{l}\text { calcium binding tyrosine } \\
\text { phosphorylation regulated }\end{array}$ \\
\hline & H3GA0018655 & 6 & $\begin{array}{l}10937985 \\
7\end{array}$ & OSBPL1A & $\begin{array}{l}\text { oxysterol binding protein } \\
\text { like } 1 \mathrm{~A}\end{array}$ \\
\hline & ASGA0029165 & 6 & $\begin{array}{l}10945221 \\
2\end{array}$ & $I M P A C T$ & $\begin{array}{l}\text { impact RWD domain } \\
\text { protein }\end{array}$ \\
\hline & & & & HRH4 & histamine receptor $\mathrm{H} 4$ \\
\hline
\end{tabular}




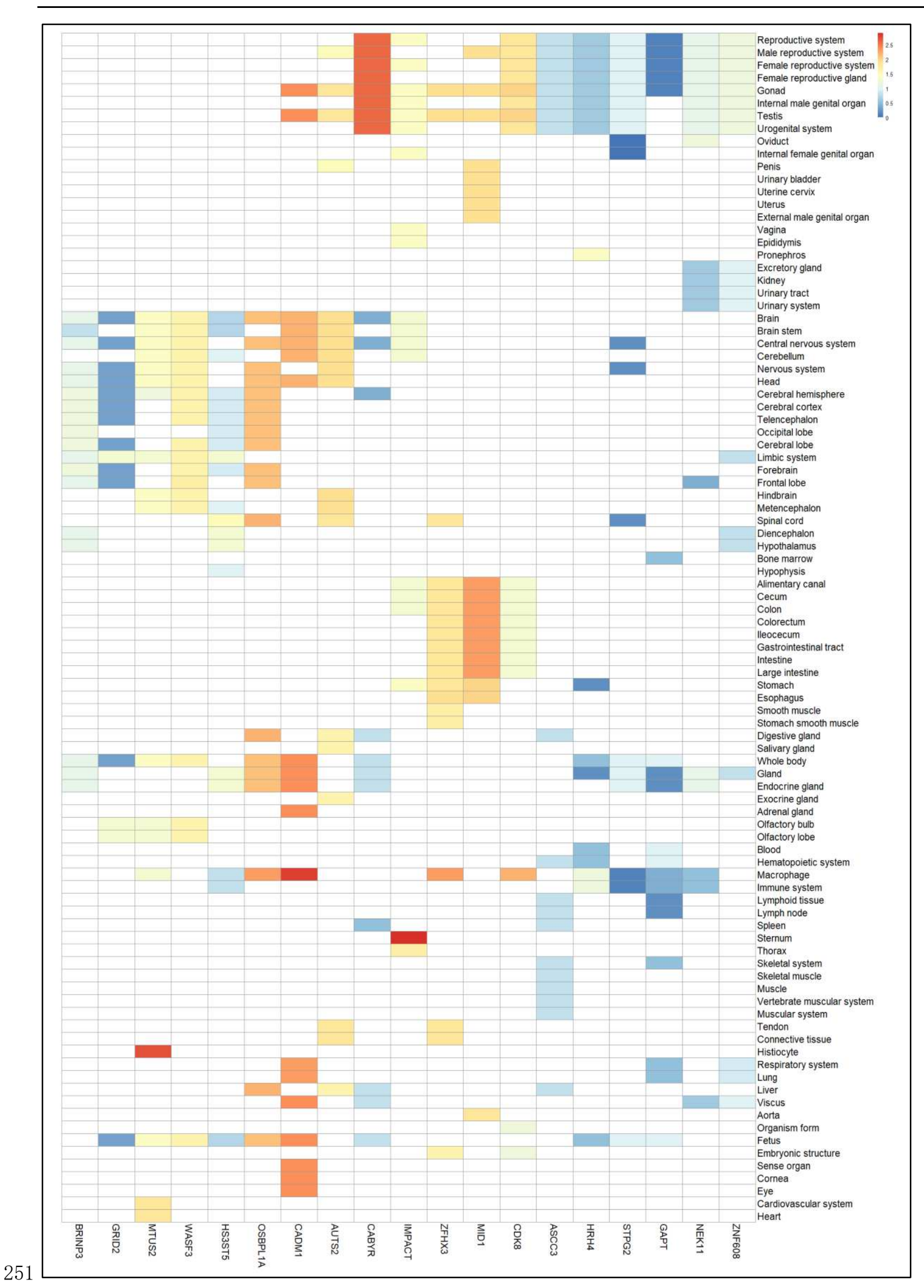

$252 \quad$ Figure 4. Digital tissue expression profiles of 19 candidate genes. 
255 In the pig industry, piglet mortality is intensively related to sow prolificacy, which is generally 256 defined as the number of piglets weaned per sow per year (PSY). It is of high importance to 257 characterize the genetic properties of piglet mortality. In this study, the piglet mortality was 258 defined as a ratio trait that was re-constructed by its component traits, which needed 259 simultaneous consideration of multiple component traits. In fact, there are many ratio traits in 260 pigs, such as feed efficiency, lean percentage, and growth rate, which do not follow the normal 261 distribution (32). For piglet mortality, the results displayed a heavily skewed distribution for 262 its phenotypes, and this trait did not follow the normal distribution. Being different from the 263 phenotype, the breeding value reveals the individual's genetic merit while removing 264 environmental effects. Considering the distribution of estimated breeding values exhibited 265 relatively little skewness, it could be inferred that the non-genetic factors might be the main 266 determinant of heavy skewness for phenotypic distribution.

267 Based on the multi-breed approach, piglet mortality was estimated as a low heritability trait, 268 with the estimations of $0.0630,0.1031$ and 0.1140 from parity I to III, respectively. There was 269 an interesting appearance that with increasing parity, the heritability for piglet mortality also 270 rises. We guess that during the first three parities, there is a growing maturation for 271 reproductive organ of gilt (33), which assumes that the more maturation of reproductive organ, 272 the lesser level of environmental factors disturbing on the fetus is happened, indicating a lower 273 environmental variance component and thus a higher heritability estimation. To our 274 knowledge, this was the first report to reveal the genetic property of piglet mortality at birth. 275 Being different from the piglet mortality at weaning, the mortality at birth has no environmental 276 effects during the lactation period, and more accurately reflects the genetic impact on the 277 mortality of fetus. In similar studies from mortality at weaning, the estimations of heritability 278 of piglet mortality were found to range from 0.03 to 0.17 (3). Although slight differences 279 occurred between the similar literatures that reported the heritability estimation of piglet 280 mortality-related traits $(34,35)$, besides our estimations, the general conclusion of low 281 heritability for piglet mortality could be supported. For the cross-trait phenotypic and genetic 282 relationships, the results revealed that all phenotypic and genetic correlations between piglet 283 mortality and its component traits were estimated to be positive. Accumulated practical 284 experiences from selection experiments showed that selection on litter size also increases the 285 number born dead, and the increasing magnitude could be up to half of the improvement of 286 litter size (36). Obviously, both phenotypic and genetic relationships supported the empirical 287 conclusion from the practical selection experiments. It indicates that the unfavorable genetic 288 correlation produces a huge challenge for simultaneously improving mortality and its 289 component traits in breeding practice.

290 In this work, we proposed a combined approach to increase the detection credibility in GWAS. 291 In the pipeline, the standard MLM, FarmCPU, BLINK, mrMLM were simultaneously utilized 292 to identify the putative SNPs, and the permutation test was followed to statistically confirm the 293 validity of putative SNPs that were detected at least by two tools. It is known that FarmCPU, 294 BLINK, mrMLM are multi-locus GWAS tools with higher detection power than single-locus 295 scan tools (26-28). There is a growing consensus that the commonly used cutoff for Bonferroni296 adjusted p-values is too conservative and stringent (29), and may miss those true SNPs with 297 medium effect size. Alternatively, the combined GWAS approach focuses on intersecting the 298 top SNPs identified by the single tools with following a permutation test procedure, which can 299 decrease the false negatives, and improve the detections of SNPs with medium effect size. It 300 would be reasonable that the combined approach based on the multi-locus tools can provide 
301 more reliable results. Following the pipeline, in total, we identified 21 SNPs that passed the 302 combined test for three parities, and it can be found that the list of the identified SNPs for each 303 parity had no overlapping. The results indicated that, in accordance with the different results 304 of heritability estimation for different parities, piglet mortality in different parities had a 305 different genetic architecture, which was consistent with the study of Onteru et al (15), and it 306 is sound to take the same trait in different parities as different traits.

307 It was highlighted that several SNPs were identified in a region between the chromosome 308 coordinates 77.2 and $126.4 \mathrm{Mb}$ on SSC 8 for parity III. Recently, two studies reported that in 309 the regions from 107.0 to $113.3 \mathrm{Mb}$ and from 144.9 to $145.5 \mathrm{Mb}$ on SSC 8, there were candidate 310 haplotypes with statistically significant effects on TNB and stillborn $(37,38)$. Considering 311 TNB and stillborn are the component traits of piglet mortality, the partial region overlap 312 supported the validity of identified SNPs on SSC 8. In addition, the validity of the identification 313 of SNPs in this study could be supported by the digital tissue expression profiles for 19 314 annotated genes from different tissues in TISSUES database. In the tissue expression profiles, 315 according to a high confidence score, most of the annotated genes were found to be expressed 316 in the reproductive and urinary system, nervous system, digestive system, and fetus. These 317 tissues are intensively related to piglet mortality. For example, Otten at el (2000) reported that 318 the prenatal stress during late gestation could result in high mortality and low birth weights for 319 piglets (39). It can confirm that the digestive system determines the efficiency of nutrition 320 intake during pregnancy (40). The genes expressed in the digestive system are closely involved 321 in fetal development and piglet mortality. Although FAT4, GATB, and MIR9802 were not 322 displayed in the heat map of tissue expression profiles, their functions were also potentially 323 involved in the piglet mortality. For example, FAT4 has been proven to regulate the apical 324 plasma membrane organization in the embryonic cerebral cortex for mammalian, indicating 325 the role in embryonic development (41). It is easy to infer that the identified genes are 326 participating in the reproductive, digestive and nervous regulation and embryo development, 327 and then contribute to piglet mortality (42).

\section{Conclusions}

329 In brief, piglet mortality at birth was found a low heritability trait. All phenotypic and genetic 330 correlations between piglet mortality and its component traits were estimated to be positive. 331 Integrating the results from standard MLM, FarmCPU, BLINK, and mrMLM, we identified 21 332 loci and 22 genes associated with piglet mortality. Most of these genes were annotated to be 333 expressed in the reproductive system, nervous system, digestive system, and embryonic 334 development, which are reasonably related to piglet losses. This study advances our 335 understanding of the genetic and genomic fundamentals of piglet mortality and also provides 336 candidate genes that could be potentially used for pig breeding programs, genomic selection, 337 and further investigations.

\section{Abbreviations}

339 GWAS: Genome-wide association study

340 MLM: mixed linear model

341 FarmCPU: Fixed and random model Circulating Probability Unification

342 BLINK: Bayesian-information and Linkage-disequilibrium Iteratively Nested Keyway

343 mrMLM: Multi-Locus Random-SNP-Effect Mixed Linear Model

344 SNP: Single-nucleotide polymorphism

345 LD: linkage disequilibrium 
346 GEBVs: genomic estimated breeding values

347 GLM: generalized linear model

348 TND: total number dead

349 TNB: total number born

350 NS: number of stillborn

351 NM: number of mummified

352 EBV: estimated breeding value

353 AI-REML: The average information restricted maximum likelihood

354 QC: quality control

355 PSY: piglets weaned per sow per year

356

357

\section{Declarations}

\section{7.1.Ethics approval and consent to participate}

359 All experiments in this study were performed according to the guidelines of the Key Lab of 360 Agriculture Animal Genetics, Breeding, and Reproduction of Ministry of Education, Animal 361 Care and Use Committee, Wuhan, China (permit HZAUSW2015-0003).

\section{7.2. Consent for publication}

363 All authors have approved the manuscript for submission.

\section{7.3.Availability of data and materials}

365 Authors do not wish to share the data due to the propriety nature of the data.

\section{7.4.Competing interests}

367 no any potential competing interests in the paper

\section{7.5.Funding}

369 This research was funded by the Natural Science Foundation of China (31672392), and 370 Earmarked Fund for China Agriculture Research System (CARS-35).

\section{7.6.Authors' contributions}

372 Writing wrote the codes, did the data analysis and editing, Meijing An; funding acquisition, 373 Mengjin Zhu; writing - review and editing, Tao Xiang, Guangliang Zhou, Yunlong Ma, 374 Xiaolei Liu, and Shuhong Zhao; methodology, Mengjin Zhu.

\section{7.7.Acknowledgements}

376 We gratefully acknowledge that Guanjun Ma, Dengdeng Ye, Qing Zhang, Quanshun Mei, 377 Guangliang Zhou, Yilong Chen, Jiuhong Nan, Mengfen Wang, Ali Liu, Shuailei Yan, Xiao 378 Peng, Haoyuan Zhang, Hailong Liu, Yinlong Liao, Xiaolong Qi, and Binxu Yin for help on 379 collecting sample tissues and extracting DNA. 
381 1. Crooks A, Hurd H, Dargatz D, Hill G. Economic Cost of Piglet Mortality in the farrowing to weaning phase: 382 A report of the NAHMS National Swine Survey. Proc Ann Mtg AASP. 1992:483-7.

383 2. Hermesch S, Luxford B, Graser H, editors. Genetic parameters for piglet mortality, within litter variation of 384 birth weight, litter size and litter birth weight. Proc Assoc Advmt Anim Breed Genet; 2001.

385 3. Varona L, Sorensen D. Joint analysis of binomial and continuous traits with a recursive model: a case study 386 using mortality and litter size of pigs. Genetics. 2014;196(3):643-51.

3874 . Knecht D, Środoń S, Duziński K. The impact of season, parity and breed on selected reproductive 388 performance parameters of sows. Archives Animal Breeding. 2015;58(1):49-56.

389 5. Ocepek M, Newberry RC, Andersen IL. Trade-offs between litter size and offspring fitness in domestic pigs 390 subjected to different genetic selection pressures. Appl Anim Behav Sci. 2017;193:7-14.

391 6. Bakoev S, Getmantseva L, Bakoev F, Kolosova M, Gabova V, Kolosov A, et al. Survey of SNPs Associated 392 with Total Number Born and Total Number Born Alive in Pig. Genes (Basel). 2020;11(5).

393 7. Andersson H, Lillpers K, Rydhmer L, Forsberg M. Influence of light environment and photoperiod on plasma 394 melatonin and cortisol profiles in young domestic boars, comparing two commercial melatonin assays. Domest 395 Anim Endocrinol. 2000;19(4):261-74.

396 8. Guo X, Su G, Christensen OF, Janss L, Lund MS. Genome-wide association analyses using a Bayesian 397 approach for litter size and piglet mortality in Danish Landrace and Yorkshire pigs. BMC Genomics. 2016;17:468.

398 9. Uimari P, Sironen A, Sevon-Aimonen ML. Whole-genome SNP association analysis of reproduction traits 399 in the Finnish Landrace pig breed. Genet Sel Evol. 2011;43:42.

400 10. Alves K, Schenkel FS, Brito LF, Robinson A. Estimation of direct and maternal genetic parameters for 401 individual birth weight, weaning weight, and probe weight in Yorkshire and Landrace pigs. J Anim Sci. 402 2018;96(7):2567-78.

403 11. Langendijk P, Plush K. Parturition and Its Relationship with Stillbirths and Asphyxiated Piglets. Animals 404 (Basel). 2019;9(11).

405 12. Roehe R, Kennedy B. Estimation of genetic parameters for litter size in Canadian Yorkshire and Landrace 406 swine with each parity of farrowing treated as a different trait. Journal of animal science. 1995;73(10):2959-70.

407 13. Irgang R, Favero JA, Kennedy BW. Genetic parameters for litter size of different parities in Duroc, Landrace, 408 and large white sows. J Anim Sci. 1994;72(9):2237-46.

409 14. Suárez M, Hermesch S, Braun JA, Graser H-U, editors. Estimates of genetic parameters for reproductive 410 traits at different parities in Australian hyperprolific Large White sows. Association for the Advancement of 411 Animal Breeding and Genetics; 2005.

412 15. Onteru SK, Fan B, Du ZQ, Garrick DJ, Stalder KJ, Rothschild MF. A whole-genome association study for 413 pig reproductive traits. Anim Genet. 2012;43(1):18-26.

414 16. de Roos AP, Hayes BJ, Goddard ME. Reliability of genomic predictions across multiple populations. 415 Genetics. 2009;183(4):1545-53.

416 17. Vanderick S, Gillon A, Glorieux G, Mayeres P, Mota RR, Gengler N. Usefulness of multi-breed models in 417 genetic evaluation of direct and maternal calving ease in Holstein and Belgian Blue Walloon purebreds and 418 crossbreds. Livest Sci. 2017;198:129-37.

419 18. Raven LA, Cocks BG, Hayes BJ. Multibreed genome wide association can improve precision of mapping 420 causative variants underlying milk production in dairy cattle. BMC Genomics. 2014;15:62.

421 19. Antunovic B, Baban M, Dobranic V, Margeta V, Mijic P, Njari B, et al. Influence of housing systems on 422 stillbirth and mortality rate in preweaning pigs farrowed by different gilt breeds. Ital J Anim Sci. 2009;8:193-5.

423 20. Vaillancourt JP, Tubbs RC. Preweaning mortality. Vet Clin North Am Food Anim Pract. 1992;8(3):685-706. 
424 21. Ramos AM, Crooijmans RP, Affara NA, Amaral AJ, Archibald AL, Beever JE, et al. Design of a high density 425 SNP genotyping assay in the pig using SNPs identified and characterized by next generation sequencing 426 technology. PLoS One. 2009;4(8):e6524.

427 22. Chang CC, Chow CC, Tellier LC, Vattikuti S, Purcell SM, Lee JJ. Second-generation PLINK: rising to the 428 challenge of larger and richer datasets. Gigascience. 2015;4:7.

429 23. Browning BL, Browning SR. A unified approach to genotype imputation and haplotype-phase inference for 430 large data sets of trios and unrelated individuals. Am J Hum Genet. 2009;84(2):210-23.

431 24. Yin L, Zhang H, Tang Z, Xu J, Yin D, Zhang Z, et al. rMVP: A Memory-efficient, Visualization-enhanced, 432 and Parallel-accelerated tool for Genome-Wide Association Study. bioRxiv. 2020:2020.08.20.258491.

433 25. Yuan X, Zhang J, Wang Y. Probability theory-based SNP association study method for identifying 434 susceptibility loci and genetic disease models in human case-control data. IEEE transactions on nanobioscience. 435 2010;9(4):232-41.

436 26. Liu X, Huang M, Fan B, Buckler ES, Zhang Z. Iterative Usage of Fixed and Random Effect Models for 437 Powerful and Efficient Genome-Wide Association Studies. PLoS Genet. 2016;12(2):e1005767.

438 27. Huang M, Liu XL, Zhou Y, Summers RM, Zhang ZW. BLINK: a package for the next level of genome-wide 439 association studies with both individuals and markers in the millions. Gigascience. 2019;8(2).

440 28. Wang SB, Feng JY, Ren WL, Huang B, Zhou L, Wen YJ, et al. Improving power and accuracy of genome441 wide association studies via a multi-locus mixed linear model methodology. Sci Rep. 2016;6:19444.

442 29. Kuo KHM. Multiple Testing in the Context of Gene Discovery in Sickle Cell Disease Using Genome-Wide 443 Association Studies. Genomics Insights. 2017;10:1178631017721178.

444 30. Huffman JE. Examining the current standards for genetic discovery and replication in the era of mega445 biobanks. Nat Commun. 2018;9(1):5054.

446 31. Palasca O, Santos A, Stolte C, Gorodkin J, Jensen LJ. TISSUES 2.0: an integrative web resource on 447 mammalian tissue expression. Database (Oxford). 2018;2018.

448 32. Yang R, Jin T, Li W. Mapping genome-wide QTL of ratio traits with Bayesian shrinkage analysis for its 449 component traits. Genetica. 2010;138(8):853-60.

450 33. Huang YH, Yang TS, Lee YP, Roan SW, Liu SH. Effects of sire breed on the subsequent reproductive 451 performances of landrace sows. Asian-Australasian Journal of Animal Sciences. 2003;16(4):489-93.

452 34. Hellbrugge B, Tolle KH, Bennewitz J, Henze C, Presuhn U, Krieter J. Genetic aspects regarding piglet losses 453 and the maternal behaviour of sows. Part 1. Genetic analysis of piglet mortality and fertility traits in pigs. Animal. 454 2008;2(9):1273-80.

455 35. Arango J, Misztal I, Tsuruta S, Culbertson M, Holl JW, Herring W. Genetic study of individual preweaning 456 mortality and birth weight in Large White piglets using threshold-linear models. Livest Sci. 2006;101(1-3):20845718 .

458 36. Varley MA, Varley MA, Varley MA, International CAB. The neonatal pig : development and survival. 459 Wallingford: CAB International; 1995. ix, 342 pages : illustrations ; $25 \mathrm{~cm} \mathrm{p.}$

460 37. Haggman J, Uimari P. Novel harmful recessive haplotypes for reproductive traits in pigs. J Anim Breed 461 Genet. 2017;134(2):129-35.

462 38. Zhang C, MacNeil MD, Kemp RA, Dyck MK, Plastow GS. Putative Loci Causing Early Embryonic 463 Mortality in Duroc Swine. Front Genet. 2018;9:655.

464 39. Otten W, Kanitz E, Tuchscherer M. Prenatal stress in pigs: effects on growth, physiological stress reactions 465 and immune function. Arch Tierzucht. 2000;43:159-64.

466 40. Johnston L, Shurson J, Whitney M. Nutritional effects on fetal imprinting in swine. 2008.

467 41. Ishiuchi T, Misaki K, Yonemura S, Takeichi M, Tanoue T. Mammalian Fat and Dachsous cadherins regulate 
468 apical membrane organization in the embryonic cerebral cortex. J Cell Biol. 2009;185(6):959-67.

469 42. Glock XT, Bilkei G. The effect of postparturient urogenital diseases on the lifetime reproductive performance 470 of sows. Can Vet J. 2005;46(12):1103-7.

\section{Additional Files}

\section{1. Additional Tables}

473 Additional Table 1. Structure of raw data sets

\begin{tabular}{ccccccccc}
\hline & spring & summer & autumn & winter & Duroc & Yorkshine & Landrace & Total \\
\hline $\begin{array}{c}\text { Parity } \\
\text { I }\end{array}$ & 1801 & 1267 & 1288 & 1717 & 581 & 3197 & 2295 & 6073 \\
$\begin{array}{c}\text { Parity } \\
\text { II }\end{array}$ & 1442 & 1180 & 1643 & 1150 & 323 & 3132 & 1960 & 5415 \\
$\begin{array}{c}\text { Parity } \\
\text { III }\end{array}$ & 1300 & 655 & 1094 & 1329 & 180 & 2626 & 1572 & 4378 \\
\hline
\end{tabular}

474 Additional Table 2. Heritability of NS, NM, TNB and TND in different parities (SE, 475 standard error in brackets).

\begin{tabular}{cccc}
\hline Traits & Parity I & Parity II & Parity III \\
\hline NS & $0.0720(0.0175)$ & $0.0880(0.0191)$ & $0.1534(0.0269)$ \\
NM & $0.0436(0.0192)$ & $0.0417(0.0213)$ & $0.0324(0.0191)$ \\
TNB & $0.2771(0.0274)$ & $0.2780(0.0307)$ & $0.3073(0.0349)$ \\
TND & $0.0851(0.0285)$ & $0.1159(0.0243)$ & $0.1207(0.0276)$ \\
\hline
\end{tabular}

476 Additional Table 3. The SNP symbols, GWAS p-values, and permutated p-values of the 477 identified SNPs.

\begin{tabular}{ccc}
\hline Identified SNP & Permutated p-values & GWAS p-values \\
\hline WU_10.2_2_133608994 & 0.0001 & $1.73 \mathrm{E}-07$ \\
WU_10.2_6_14929389 & 0.0001 & $1.17 \mathrm{E}-06$ \\
ALGA0121819 & 0.0001 & $6.75 \mathrm{E}-10$ \\
WU_10.2_9_47540573 & 0.0001 & $7.46 \mathrm{E}-06$ \\
WU_10.2_10_4318367 & 0.0002 & $1.10 \mathrm{E}-05$ \\
WU_10.2_X_7708900 & 0.0001 & $3.47 \mathrm{E}-07$ \\
MARC0052132 & 0.0001 & $2.44 \mathrm{E}-07$ \\
WU_10.2_7_6945588 & 0.0001 & $5.67 \mathrm{E}-07$ \\
ALGA0048798 & 0.0001 & $1.23 \mathrm{E}-07$ \\
WU_10.2_8_135384225 & 0.0001 & $1.20 \mathrm{E}-05$ \\
ALGA0090390 & 0.0002 & $7.25 \mathrm{E}-05$ \\
DRGA0001119 & 0.0001 & $4.96 \mathrm{E}-05$ \\
Affx-115201707 & 0.0002 & $2.00 \mathrm{E}-05$ \\
ALGA0036320 & 0.0001 & $8.39 \mathrm{E}-06$ \\
H3GA0018655 & 0.0001 & $1.33 \mathrm{E}-05$ \\
ASGA0029165 & 0.0001 & $1.50 \mathrm{E}-05$
\end{tabular}




\begin{tabular}{ccc}
\hline MARC0113660 & 0.0001 & $4.76 \mathrm{E}-05$ \\
DRGA0008818 & 0.0001 & $4.76 \mathrm{E}-05$ \\
ALGA0060358 & 0.0001 & $1.04 \mathrm{E}-08$ \\
ASGA0049501 & 0.0001 & $2.60 \mathrm{E}-05$ \\
ASGA0055572 & 0.0001 & $9.25 \mathrm{E}-06$
\end{tabular}

478 Note: For the p-values in the table, they were the smallest ones among the p-values from 479 different tools.

480 Additional Table 4. Descriptive statistics of phenotype (SD, Standard Deviation; C.V, 481 Coefficient of Variation)

\begin{tabular}{cccccc}
\hline & Mean & Min & Max & SD & C.V \\
\hline Parity I & 0.079385972 & 0 & 1 & 0.134816603 & 1.698242139 \\
Parity II & 0.073242952 & 0 & 1 & 0.12364918 & 1.688205833 \\
Parity III & 0.068735823 & 0 & 1 & 0.111656107 & 1.624423818 \\
\hline
\end{tabular}

482 Additional Table 5. The top ten SNPs identified by the standard MLM, FarmCPU, BLINK, 483 and mrMLM for piglet mortality from Parity I-III

\begin{tabular}{|c|c|c|c|c|c|c|c|}
\hline \multicolumn{8}{|c|}{ Parity I } \\
\hline \multicolumn{2}{|c|}{ MLM } & \multicolumn{2}{|c|}{ FarmCPU } & \multicolumn{2}{|c|}{ BLINK } & \multicolumn{2}{|c|}{ mrMLM } \\
\hline SNP & p-value & SNP & $\begin{array}{c}\text { p- } \\
\text { value }\end{array}$ & SNP & $\begin{array}{c}\text { p- } \\
\text { value }\end{array}$ & SNP & $\mathrm{p}$-value \\
\hline WU_10.2_2_1 & $1.04 \mathrm{E}$ & WU_10.2_2_ & $2.99 \mathrm{E}-$ & ALGA01 & $6.75 \mathrm{E}-$ & WU_10.2_1_ & $6.48336 \mathrm{E}$ \\
\hline 33608994 & -06 & 1660824 & 09 & 21819 & 10 & 303761600 & -08 \\
\hline ALGA0 & $2.94 \mathrm{E}$ & WU_10.2_6 & $1.17 \mathrm{E}-$ & ASGA0 & $2.06 \mathrm{E}-$ & WU_10.2_15_ & $1.78 \mathrm{E}$ \\
\hline 121819 & -06 & _14929389 & 06 & 054479 & 08 & 141565227 & -06 \\
\hline WU_10.2_X_7 & $4.08 \mathrm{E}$ & MARC0 & $5.24 \mathrm{E}-$ & WU_10.2_2 & $1.73 \mathrm{E}-$ & Affx-114 & $4.93 \mathrm{E}$ \\
\hline 708900 & -06 & 045581 & 06 & _1336089994 & 07 & 978229 & -06 \\
\hline MARC0 & $1.66 \mathrm{E}$ & ALGA0 & $5.80 \mathrm{E}-$ & WU_10.2_X & $3.47 \mathrm{E}-$ & Affx-1147 & $4.93 \mathrm{E}$ \\
\hline 008576 & -05 & 121819 & 06 & _7708900 & 07 & 04997 & -06 \\
\hline ALGA0 & $2.15 \mathrm{E}$ & WU_10.2_X_ & $6.16 \mathrm{E}-$ & WU_10.2_8_ & $3.20 \mathrm{E}-$ & Affx-1146 & $1.74 \mathrm{E}$ \\
\hline 004972 & -05 & 136142589 & 06 & 5737649 & 05 & 89732 & -05 \\
\hline MARC0 & $2.74 \mathrm{E}$ & WU_10.2_9_ & $7.46 \mathrm{E}-$ & WU_10.2_9_ & $4.61 \mathrm{E}-$ & MARC0 & $2.51 \mathrm{E}$ \\
\hline 078678 & -05 & $47 \overline{5} 40573$ & 06 & 126944287 & 04 & 050498 & -05 \\
\hline WU_10.2_X & $3.51 \mathrm{E}$ & MARC0 & $7.65 \mathrm{E}-$ & M1GA0 & $4.91 \mathrm{E}-$ & DRGA0 & $3.72 \mathrm{E}$ \\
\hline _124874052 & -05 & 022036 & 06 & 004763 & 04 & 002303 & -05 \\
\hline Affx-114 & $3.64 \mathrm{E}$ & ALGA0 & $8.23 \mathrm{E}-$ & WU_10.2_10 & $5.06 \mathrm{E}-$ & ALGA0 & $3.72 \mathrm{E}$ \\
\hline 980032 & -05 & 049751 & 06 & 4318367 & 04 & 009074 & -05 \\
\hline ALGA00 & $4.16 \mathrm{E}$ & H3GA0 & $9.83 \mathrm{E}-$ & WU_10.2_9 & $5.49 \mathrm{E}-$ & H3GA00 & $5.11 \mathrm{E}$ \\
\hline 07070 & -05 & 009377 & 06 & _47540573 & 04 & 49299 & -05 \\
\hline ASGA0 & $5.87 \mathrm{E}$ & WU_10.2_10 & $1.10 \mathrm{E}-$ & WU_10.2_6_ & $5.59 \mathrm{E}-$ & ASGA0 & $5.49 \mathrm{E}$ \\
\hline 063018 & -05 & _4318367 & 05 & 14929389 & 04 & 095137 & -05 \\
\hline \multicolumn{8}{|c|}{ Parity II } \\
\hline \multicolumn{2}{|c|}{ MLM } & \multicolumn{2}{|c|}{ FarmCPU } & \multicolumn{2}{|c|}{ BLINK } & \multicolumn{2}{|c|}{ mrMLM } \\
\hline SNP & $\mathrm{p}$-value & SNP & $\begin{array}{c}\mathrm{p}- \\
\text { value }\end{array}$ & SNP & $\begin{array}{c}\text { p- } \\
\text { value }\end{array}$ & SNP & p-value \\
\hline WU_10.2_8 & $1.20 \mathrm{E}$ & WU_10.2_3_ & $6.57 \mathrm{E}-$ & DRGA00 & $1.04 \mathrm{E}-$ & ALGA0 & $1.61 \mathrm{E}$ \\
\hline _135384225 & -05 & 124682588 & 11 & 04397 & 07 & 052861 & -07 \\
\hline WU_10.2_7 & $3.40 \mathrm{E}$ & WU_10.2_7 & $9.78 \mathrm{E}-$ & ALGA0 & $1.23 \mathrm{E}-$ & M1GA0 & $5.93 \mathrm{E}$ \\
\hline _6945588 & -05 & _8690791 & 08 & 048798 & 07 & 012952 & -07 \\
\hline ALGA0 & $3.53 \mathrm{E}$ & WU_10.2_15 & $2.62 \mathrm{E}-$ & ALGA0 & $2.18 \mathrm{E}-$ & ASGA0 & $1.87 \mathrm{E}-$ \\
\hline 048798 & -05 & 118972045 & 07 & 006121 & 07 & 080428 & 05 \\
\hline
\end{tabular}




\begin{tabular}{|c|c|c|c|c|c|c|c|}
\hline MARC0 & $3.92 \mathrm{E}$ & WU_10.2_1 & $3.90 \mathrm{E}-$ & MARC0 & 2.44E- & MARC00 & $2.42 \mathrm{E}$ \\
\hline 052132 & -05 & 8_7356014 & 06 & 052132 & 07 & 55383 & -05 \\
\hline WU_10.2_8_ & $6.44 \mathrm{E}$ & $\overline{\mathrm{H}} 3 \mathrm{GA} 00$ & $1.81 \mathrm{E}-$ & WU_10.2_ & 5.67E- & MARC0 & $3.80 \mathrm{E}$ \\
\hline $13 \overline{5} 464992$ & -05 & 46969 & 05 & 7_69-15588 & 07 & 066282 & -05 \\
\hline WU_10.2_ & $6.63 \mathrm{E}$ & WU_10.2_13 & $3.27 \mathrm{E}-$ & WU_10.2_1 & $1.10 \mathrm{E}-$ & WU_10.2_6_ & $6.84 \mathrm{E}$ \\
\hline 4_3739598 & -05 & _30474727 & 05 & 1_82-10196̄ & 04 & $11 \overline{6} 413991$ & -05 \\
\hline ALGA00 & $7.25 \mathrm{E}$ & ASGA0 & $3.72 \mathrm{E}-$ & ALGA00 & $2.50 \mathrm{E}-$ & WU_10.2_6_ & $7.17 \mathrm{E}$ \\
\hline 90390 & -05 & 007897 & 05 & 90390 & 04 & 132959422 & -05 \\
\hline WU_10.2_8 & $7.77 \mathrm{E}$ & ASGA0 & $3.75 \mathrm{E}-$ & MARC0 & 3.49E- & ALGA0 & $1.31 \mathrm{E}$ \\
\hline _104296859 & -05 & 009531 & 05 & 010165 & 04 & 001726 & -04 \\
\hline ALGA0 & $7.88 \mathrm{E}$ & WU_10.2_8_ & $4.04 \mathrm{E}-$ & ASGA00 & 5.07E- & ALGA0 & $1.86 \mathrm{E}$ \\
\hline 114423 & -05 & 135384225 & 05 & 52141 & 04 & 097061 & -04 \\
\hline MARC0 & $8.09 \mathrm{E}$ & MARC0 & $5.31 \mathrm{E}-$ & ALGA00 & $5.88 \mathrm{E}-$ & ALGA0 & $1.86 \mathrm{E}$ \\
\hline 089453 & -05 & 070175 & 05 & 52390 & 04 & 097066 & -04 \\
\hline \multicolumn{8}{|c|}{ Parity III } \\
\hline \multicolumn{2}{|c|}{ MLM } & \multicolumn{2}{|c|}{ FarmCPU } & \multicolumn{2}{|c|}{ BLINK } & \multicolumn{2}{|c|}{ mrMLM } \\
\hline SNP & $\mathrm{p}$-value & SNP & $\begin{array}{c}\mathrm{p}- \\
\text { value }\end{array}$ & SNP & $\begin{array}{c}\text { p- } \\
\text { value }\end{array}$ & SNP & $\mathrm{p}$-value \\
\hline ALGA0 & $9.92 \mathrm{E}$ & WU_10.2_1 & $6.16 \mathrm{E}-$ & ALGA0 & $7.6 \mathrm{E}-$ & ALGA0 & $1.04 \mathrm{E}$ \\
\hline 060358 & -07 & $0 \_32348084$ & 17 & 122208 & 18 & 060358 & -06 \\
\hline ALGA0 & $8.39 \mathrm{E}$ & WU_10.2_ & 4.47E- & WU_10.2_X & $3.9 \mathrm{E}-$ & ALGA0 & $9.42 \mathrm{E}$ \\
\hline 036320 & -06 & X_7317072 & 10 & -139666324 & 14 & 036320 & -06 \\
\hline ASGA0 & $9.25 \mathrm{E}$ & WU_10.2_3 & $4.89 \mathrm{E}-$ & ALGA0 & $1.4 \mathrm{E}-$ & ASGA0 & $1.06 \mathrm{E}$ \\
\hline 055572 & -06 & {$[12 \overline{7} 030944$} & 09 & 049681 & 11 & 055572 & -05 \\
\hline H3GA00 & $1.33 \mathrm{E}$ & ALGA0 & $5.7 \mathrm{E}-$ & WU_10.2_14 & 3.36E- & H3GA0 & $1.46 \mathrm{E}$ \\
\hline 18655 & -05 & 018083 & 09 & _139115957 & 11 & 018655 & -05 \\
\hline ASGA0 & $1.5 \mathrm{E}$ & ALGA0 & $6.96 \mathrm{E}-$ & $\overline{\mathrm{WU}} \_10.2 \_15$ & $1.15 \mathrm{E}-$ & ASGA00 & $1.66 \mathrm{E}$ \\
\hline 029165 & -05 & 095726 & 09 & 21804958 & 10 & 29165 & -05 \\
\hline ASGA0 & $2.6 \mathrm{E}$ & WU_10.2_1 & $7.29 \mathrm{E}-$ & WU_10.2_X & $1.11 \mathrm{E}-$ & Affx-115 & $2.00 \mathrm{E}$ \\
\hline 049501 & -05 & 5_20997846 & 09 & _34786795 & 09 & 201707 & -05 \\
\hline Affx-1152 & $3.32 \mathrm{E}$ & ALGA0 & $1.04 \mathrm{E}-$ & $\overline{\mathrm{W} U} \_10.2 \_1$ & $1.44 \mathrm{E}-$ & ASGA0 & $2.64 \mathrm{E}$ \\
\hline 01707 & -05 & 060358 & 08 & _ 47087424 & 09 & 049501 & -05 \\
\hline MARC0 & $4.76 \mathrm{E}$ & WU_10.2_X & $1.8 \mathrm{E}-$ & $\overline{\mathrm{WU}} \_10.2 \_5$ & $2.68 \mathrm{E}-$ & DRGA00 & $4.96 \mathrm{E}$ \\
\hline 113660 & -05 & _37383826 & 08 & $\_85471520$ & 09 & 01119 & -05 \\
\hline DRGA0 & $4.76 \mathrm{E}$ & H3GA0 & $2.81 \mathrm{E}-$ & WU_10.2_ & $5.96 \mathrm{E}-$ & MARC0 & $5.68 \mathrm{E}$ \\
\hline 008818 & -05 & 042609 & 08 & 7_47̄77306 & 09 & 113660 & -05 \\
\hline DRGA & $6.24 \mathrm{E}$ & MARC0 & $4.51 \mathrm{E}-$ & ASGA0 & $1.21 \mathrm{E}-$ & DRGA0 & $5.68 \mathrm{E}$ \\
\hline 0001119 & -05 & 002720 & 07 & 100851 & 08 & 008818 & -05 \\
\hline
\end{tabular}

484 Note: For the p-values in the table, they were the smallest ones among the p-values from 485 different tools. 
(a) Distribution of Mortality Phenotype from parity 1



(d) Distribution of Mortality EBV from parity 1

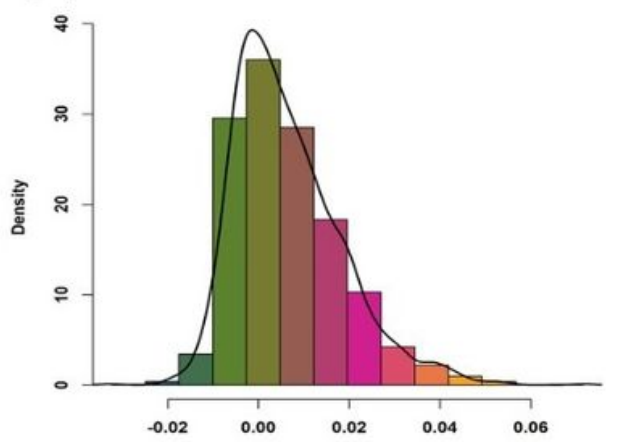

(b)



(e) Distribution of Mortality EBV from parity II

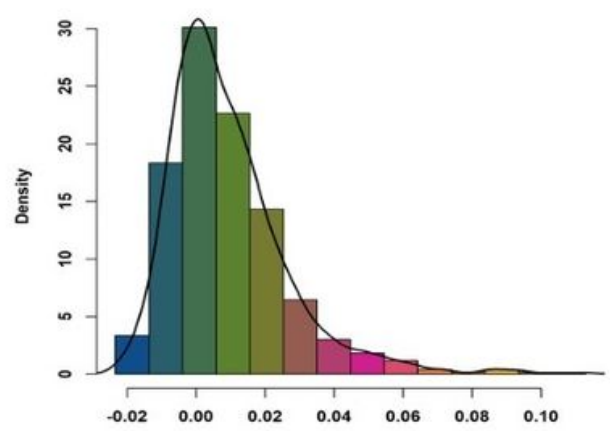

(c) Distribution of Mortality Phenotype from parity III

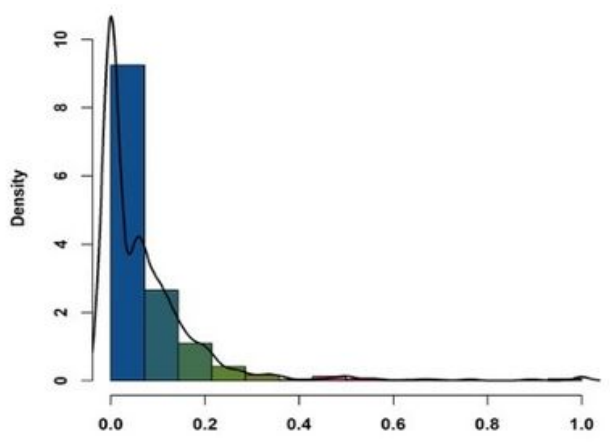

(f) Distribution of Mortality EBV from parity III

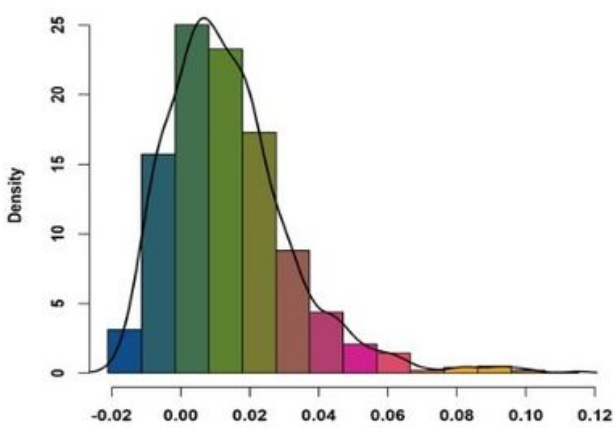

\section{Figure 1}

The phenotypic and EBV's distributions of piglet mortality from the three parities. Sub-figures from a to $c$ represented the phenotypic distributions from parity I to parity III, and sub-figures from $d$ to f represented the distributions of EBVs from parity I to III, respectively.

(a)

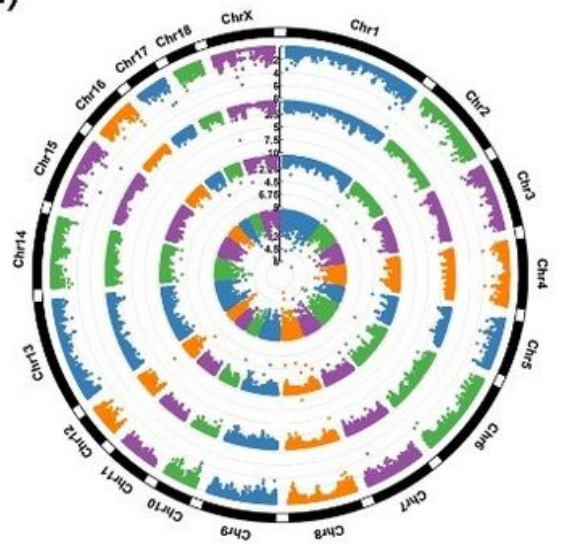

(b)

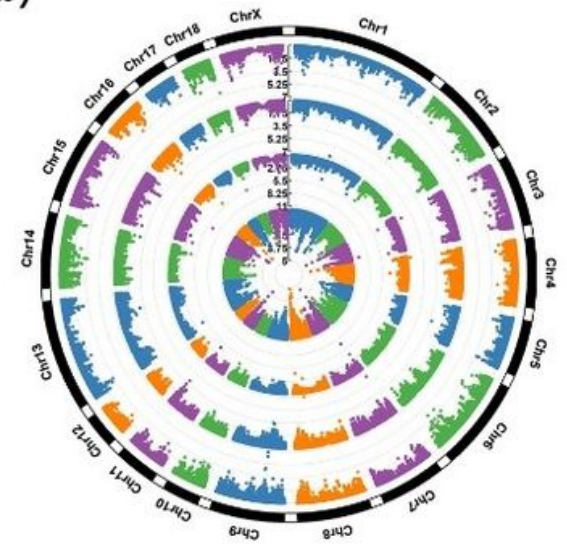

(c)



Figure 2 
Circular-Manhattan of piglet mortality of different parities. a. Circular-Manhattan plots of MLM, FarmCPU, BLINK, mrMLM for parity l; b. Circular-Manhattan plots of MLM, FarmCPU, BLINK, mrMLM for parity II; c. Circular-Manhattan plots of MLM, FarmCPU, BLINK, mrMLM for parity III; and from inner to outer, they were MLM, FramCPU, BLINK and mrMLM, respectively.
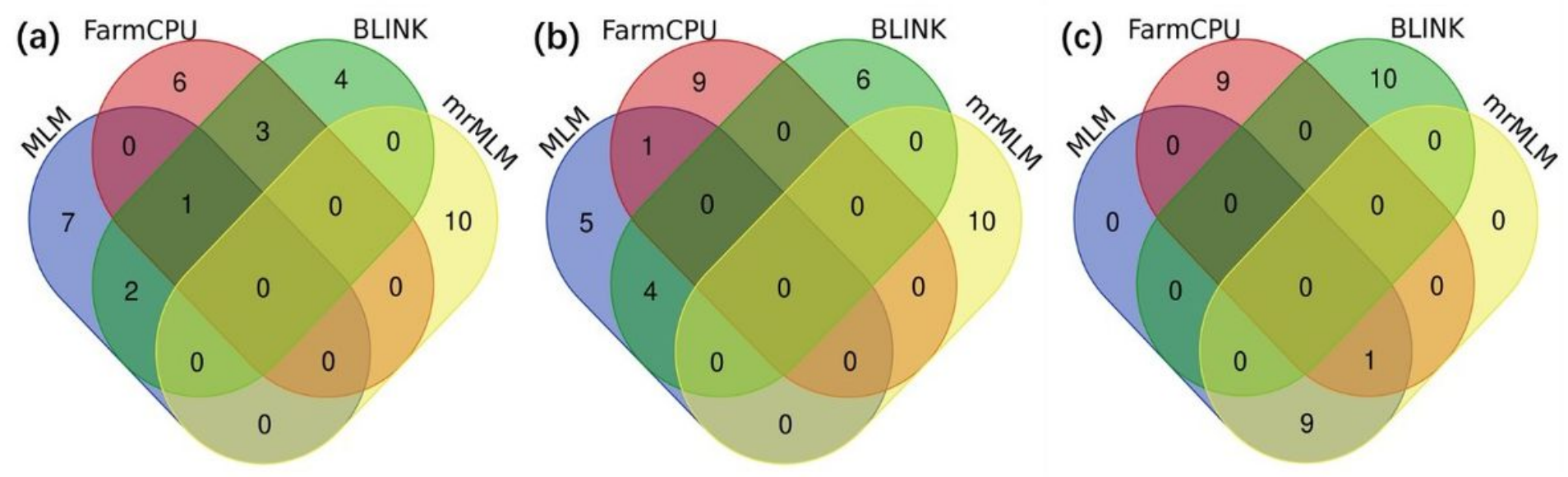

Figure 3

The Venn diagrams of identified SNPs in piglet mortality from parity I, II, III a. Venn diagrams of MLM, FarmCPU, BLINK, mrMLM method for parity I. There were 6 SNPs intersected by at least two tools; $b$. Venn diagrams of MLM, FarmCPU, BLINK, mrMLM method for parity II. There were 5 SNPs intersected by two tools; c. Venn diagrams of MLM, FarmCPU, BLINK, mrMLM method for parity III. There were 10 SNPs intersected by two tools. 


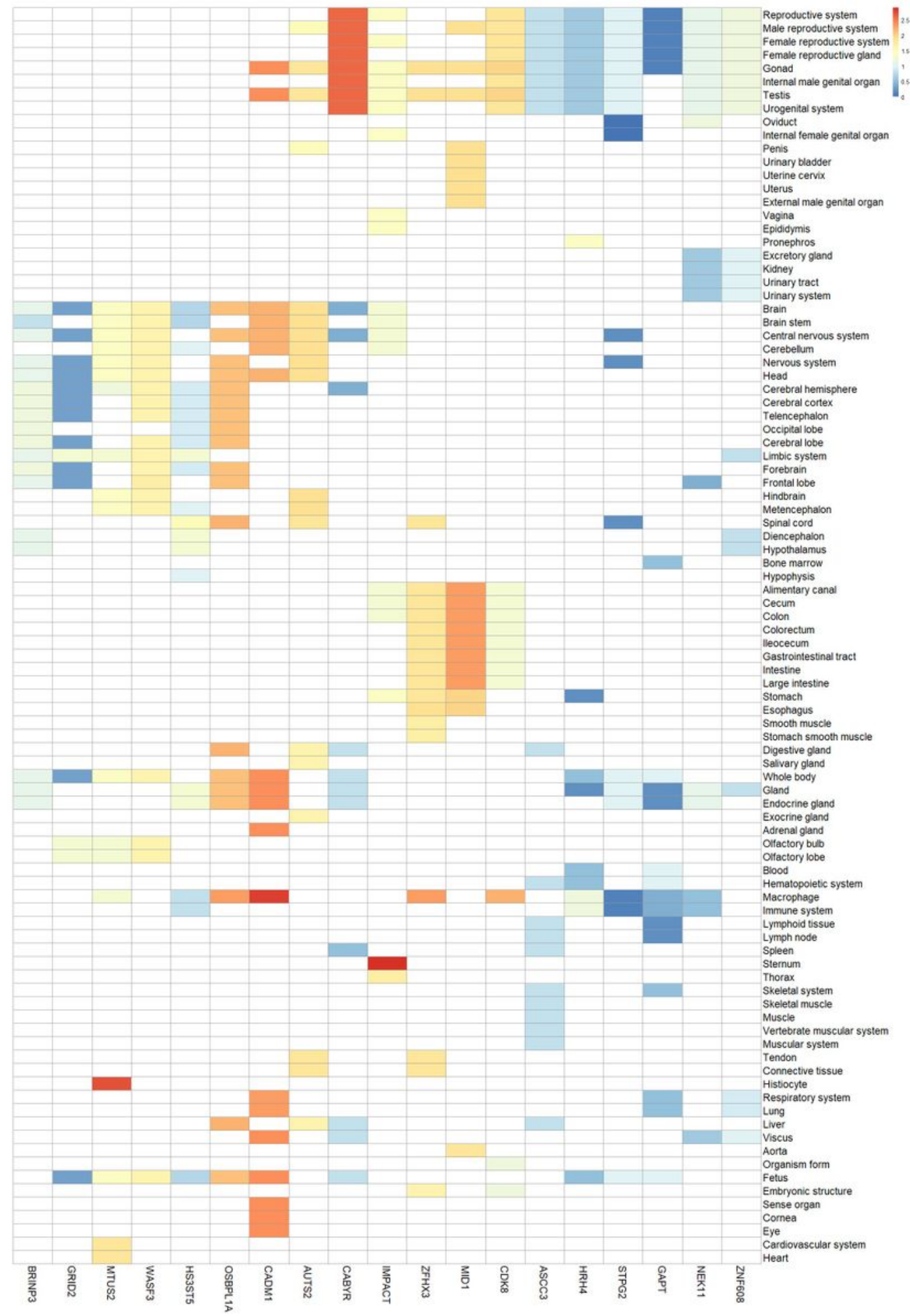

Figure 4

Digital tissue expression profiles of 19 candidate genes. 